\title{
Miamia maimai n. sp., a new Pennsylvanian stem-orthopteran insect, and a case study on the application of cladotypic nomenclature
}

\author{
Olivier Béthoux ${ }^{1,2}$, Junjie $\mathrm{Gu}^{1}$, Yanli Yue ${ }^{3}$ and Dong Ren ${ }^{*}, 1$ \\ ${ }^{1}$ College of Life Sciences, Capital Normal University, 105 Xisanhuanbeilu, Haidian District, Beijing 100048, China. \\ E-mails: rendong@mail.cnu.edu.cn, orthoptera_gu@yahoo.cn \\ 240 rue d'Aveillans, 38770 La Motte d'Aveillans, France. E-mail: obethoux@yahoo.fr \\ ${ }^{3}$ College of Life Sciences, Ningxia University, 539 West Helanshan Road, Xixia District, Yinchuan 750021, China. \\ E-mails: rendong@mail.cnu.edu.cn, yueyanli0407@yahoo.cn
}

\begin{abstract}
Received 6 January 2012

Accepted 4 April 2012

Published 3 August 2012

\section{Key Words}

Archaeorthoptera

genus name

Lanham's species name

Late Carboniferous

A new stem-orthopteran insect assignable to the - traditional - genus and the - cladotypic-defined - taxon Miamia Dana, 1864 is described based on abundant material collected from the Xiaheyan locality (Ningxia, China; Early Pennsylvanian). Intra-specific wing venation variability in Miamia maimai $\mathrm{n}$. sp. is appreciated based on wing pairs of single individuals, and on a complete series of conditions. Rare variants are reported. Details of head and leg morphology are documented: the new species possesses a five-segmented tarsus provided with paired claws and arolium, and labial palps with at least four segments, probably five. The nomenclatural section is conducted under the cladotypic nomenclatural procedure, but in a way largely consistent with the traditional usage. This experiment demonstrates that a combination composed of a 'genus level-taxon' name previously associated with a definition and type material (e.g. Miamia), a specific epithet (e.g. maimai), and authorship information (e.g. Béthoux et al. 2012), with further mention to 'Miamia maimai' or 'M. maimai', provides a suitable reference to the species under all nomenclatural procedures, including the traditional one.
\end{abstract}

\section{Introduction}

Although rules constraining the naming of organisms have been debated for a couple of centuries (Dayrat 2010), the general rejection of paraphyletic assemblages as natural groups in favor of monophyletic ones only (Hennig 1966) prompted new developments in the field of nomenclature. This is particularly true of the last decade, with the development of the PhyloCode (Cantino \& de Queiroz 2010). Another alternative approach, namely the cladotypic one, was proposed recently (Béthoux 2007a, b, 2010). In brief, it enforces the association of a taxon name to the formulation of a character state (presumably derived), and to two type specimens ('cladotypes') exhibiting the given character state (cladotypes belong to the 'cladotypic species' of the taxon). Under this procedure ranks are not solicited, a taxon being considered simply as a species that underwent a cladogenesis event. Taxon names are written in italics with majuscule. Lanham's species names, composed of the existing specific epithet associated with authorship information only (Lanham 1965; Dayrat et al. 2004), are favored. Advantages of the cladotypic procedure have been investigated elsewhere based on theoretical cases (Béthoux 2010), and a few actual applications have been attempted.

Among them, the genus name Miamia Dana, 1864 has been 'adapted' as a rankless taxon (Béthoux 2008a). As mandatory, it has been associated to a defining character state (viz. 'in forewings, $\mathrm{CuPa}$ fuses with $\mathrm{M}+\mathrm{CuA}^{\prime}$ ) and to two cladotypic species (viz. bronsoni Dana, 1864, and silvatica Laurentiaux \& Laurentiaux-

* Corresponding author 
Vieira, 1980). The species rossorum Béthoux \& Jarzembowski, 2010 was later assigned to this taxon, as it possesses the corresponding defining character state. The taxon Miamia is considered as member of the larger taxon Archaeorthoptera, itself duly associated to a character formulation and cladotypic species (Béthoux 2007c). Members of the taxon Archaeorthoptera basically are stem-orthopterans, i.e. stem-representatives of extant grasshoppers, locusts, crickets, and katydids.

Material belonging to a new species that could be assigned to Miamia was collected from the locality near Xiaheyan village (Zhongwei City, China; Tupo Formation), intensively sampled by the research team of DR. The study of the corresponding fauna is ongoing. It includes stem-odonatopterans (Zhang et al. 2006; Ren et al. 2008), stem-blattodeans (Guo et al. in press; Zhang et al. in press), stem-grylloblattodeans (Peng et al. 2005; Cui et al. 2011), Archaeorthoptera (Prokop \& Ren 2007; Liu et al. 2009; Gu et al. 2011; Béthoux et al. 2012), stem-plecopterans (Béthoux et al. 2011), and members of extinct palaeopteran groups (Prokop \& Ren 2007). The cladotypic nomenclatural procedure is sufficiently well-developed in the present case to allow the new Miamia species to be erected in a way consistent with both the traditional and the cladotypic usages, and to investigate implications of the actual application of the latter procedure.

\section{Material and methods}

All fossil specimens described herein are housed at the Key Lab of Insect Evolution and Environmental Changes, College of Life Sciences, Capital Normal University, Beijing (China; curation by Ren Dong). Fossil specimens were examined using a LEICA MZ12.5 dissecting microscope and illustrated with the aid of a drawing tube. Final drawings were inked by hand and polished digitally on Adobe Photoshop. Photographs were taken using a Canon EOS 450D digital camera coupled to a Canon $50 \mathrm{~mm}$ macro lens (and an extension tube as appropriate), and to a Canon MP-E $65 \mathrm{~mm}$ macro lens. All photographs of fossil specimens are dry-ethanol composites. The light-mirror technique was used as indicated in figure captions [see details for this technique in Béthoux \& Briggs (2008)]. Photographs were processed with Adobe Photoshop.

We use the cladotypic nomenclatural procedure (Béthoux 2007a, b, 2010) for taxa other than species, and suggestions by Dayrat et al. 2004; and references therein) for species names. Except for the formal systematic section, mixing both procedures, Linnaean taxon names are avoided throughout this contribution, 'vernacularized' names being preferred (for example, 'orthopterans' rather than 'Orthoptera'). The choice of taxonomic procedure is based on the decision of one of us $(\mathrm{OB})$, based on the presumed higher optimality of the cladotypic procedure (Béthoux 2010), but does not imply the support of other authors (JJG, YLY \& DR) to all aspects of this procedure. The discussion on nomenclature is the responsibility of the former author.

The wing venation nomenclature used in this paper is based on conjectures of topological homology proposed by Béthoux \& Nel (2002) for Archaeorthoptera, itself based on that elaborated for Orthoptera [Béthoux \& Nel (2001); and see Béthoux (2008b) for discussion and references on alternative interpretations; and Rasnitsyn \& Aristov (2010)]. Corresponding abbreviations are: ScP, posterior Subcosta; R, Radius; RA, anterior Radius; RP, posterior Radius; M, Media; $\mathrm{CuA}$, anterior Cubitus; $\mathrm{CuP}$, posterior Cubitus; $\mathrm{CuPa}$, anterior branch of $\mathrm{CuP}$; $\mathrm{CuPb}$, posterior branch of $\mathrm{CuP}$; $\mathrm{AA}$, anterior Analis Other abbreviations are as follows: LFW, left forewing; RFW, right forewing; LHW, left hind wing; RHW, right hind wing; an, antennae; p, pedicel; s, scape; e, eye; c, claw; ar, arolium.

Following Cui et al. (2011), the branching pattern of $\mathrm{M}$ is indicated by brackets and numbers (for example, $(1,2)$ indicates a simple anterior branch and a forked posterior one). In several cases the exact number of branches of a given vein is uneasy to estimate because forks occurring near the wing margin give rise to veinlets that could just be cross-veins [distinction between vein, veinlet, and cross-vein might be artificial to some extent; Béthoux \& Schneider (2010)]. In descriptions we provide a range for such cases (e.g., $\mathrm{CuA}+\mathrm{CuPa}$ has 7-8 terminal branches in the specimen CNU-NX1-276).

In the general description, for numbers of branches of a particular vein, we indicate the usual condition, and provide the minimum, maximum, and average numbers as follows: (minimum/average/maximum; $n=$ number of observations). In order to deal with undecided cases (such as 7 or 8 branches in a single specimen; see above), we calculated an average based on minimum values only, another on maximum value only, and an average of both averages. The latter only is indicated.

Regarding measurements of the 'RP - M connection', we used a positive value in the case of a RP $+M$ fusion. In cases where this fusion is lacking, the lowest width of the area between RP and M was measured and given a negative value. Calculating the average of these values allowed us to estimate the average condition of RP \& $M$ in the species. For example a low and positive average figure would indicate the occurrence of a short fusion, on average, while a high negative value would indicate RP and $\mathrm{M}$ to be widely distant, on average. This approach was prompted by the fact that the series of states ranging from ' $\mathrm{RP}$ and $\mathrm{M}$ distinct' to ' $\mathrm{RP}$ and $\mathrm{M}$ fused for a long distance' forms a continuum, better appreciated by a single measurement.

\section{Systematic palaeontology}

Superorder Archaeorthoptera Béthoux \& Nel, 2002/ Taxon Archaeorthopera nom. Béthoux \& Nel, 2002, dis.-typ. Béthoux, 2007c

Genus Miamia Dana, 1864/Taxon Miamia nom. Dana 1864, dis.-typ. Béthoux, 2008a

\section{Miamia maimai n. sp.}

Figures 1-4

Derivation of name. Derived from the words 'mái', 'buried' in Chinese, and 'mài', 'venation' in Chinese, altogether meaning 'buried (wing) veins'; and anagram of Miamia, the genus \& taxon to which the species is assigned herein.

Material. Holotype specimen CNU-NX1-280 (Fig. 1), specimens CNU-NX1-272 (Figs 4A-C), -273 (Figs 3A-C), -274 (Fig. 3E), -275 (Fig. 3D), -276 (Fig. 4E), -277 (Fig. 3F), -278 (Figs 2A-D), -279 (Fig. 4D), -319 (Figs 2E-H), and additional undescribed specimens CNU-NX1-284, -296, -299, -313, 316, -481 to -486 .

Formation and age. Xiaheyan Village, Zhongwei City, Tupo Formation (Ningxia Hui Autonomous Region, China); Early Pennsylvanian (Lu et al. 2002).

Differential diagnosis. Forewings: stem of $\mathrm{M}$ simple for a long distance; frequent fusion of a branch $\mathrm{M}$ with RP. 


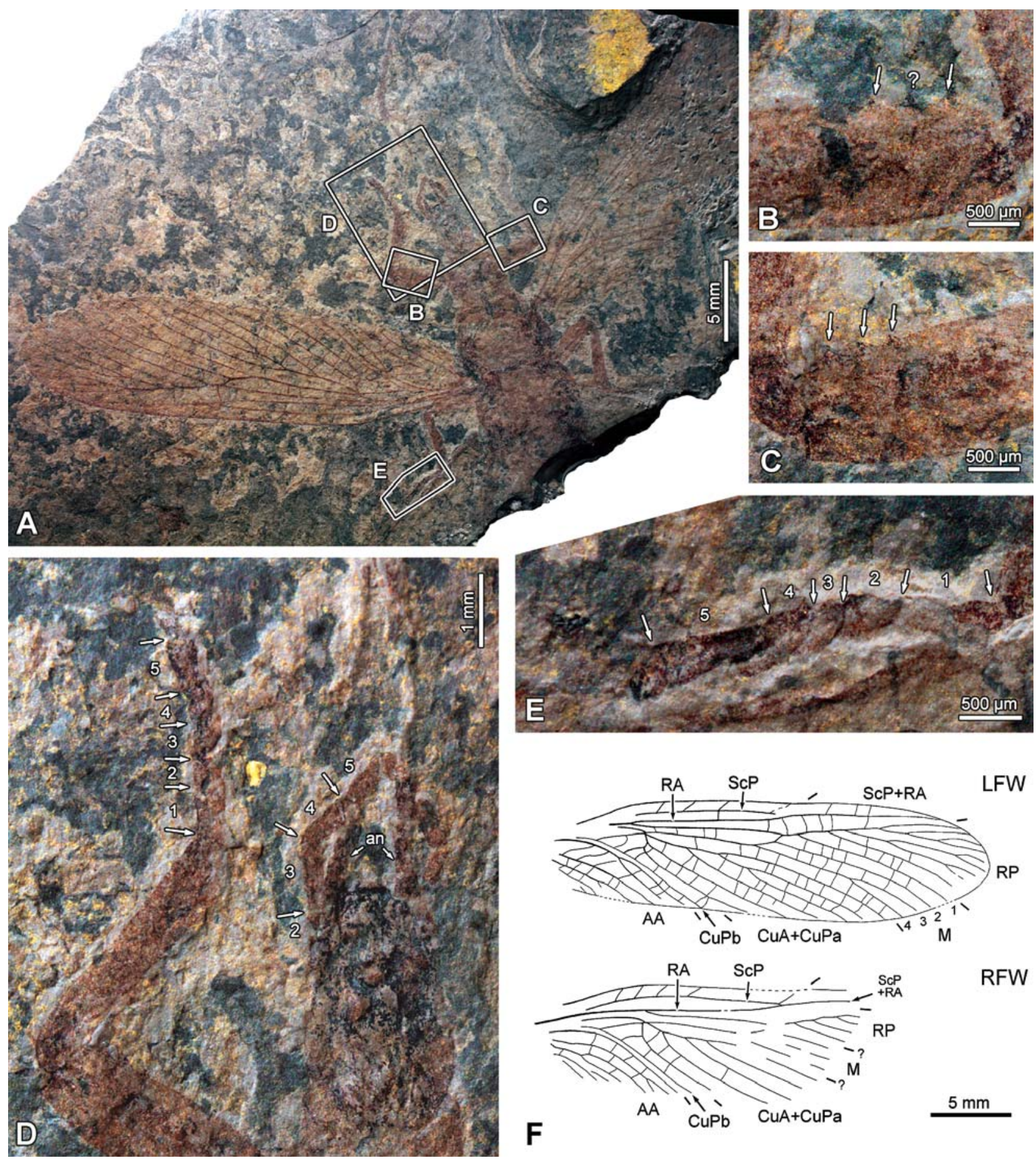

Figure 1. Miamia maimai n. sp., holotype specimen CNU-NX1-280 (see text for abbreviations); A. Habitus; B, C. Fore-legs, details of distal part of femur, as located on A (arrows indicate spines); B. Left fore-leg; C. Right fore-leg; D. Head and left foreleg, as located on A (arrows indicate approximate segments limits); E. Left mid-leg, detail of tarsus, as located on A (arrows indicate approximate segments limits); F. Drawings of left and right forewings.

\section{General description}

Head. Antennae filiform, with 23 segments (or with just a few more terminal ones); scape and pedicle short, the former slightly broader than the latter; palpi with four observed segments (probably five total).

Legs. Fore femora stout and slightly dilated, 3.0$3.7 \mathrm{~mm}$ long, $1.1-1.3 \mathrm{~mm}$ wide, with three small spines close to apex; fore tibiae $3.9 \mathrm{~mm}$ long; middle tibiae $3.7-4.2 \mathrm{~mm}$ long; hind femora about $5.2 \mathrm{~mm}$, with three or four small spines close to apex; all tarsi five-segmented, with paired claws and arolium.

Wings. Convexity of veins not evident.

Forewing. Length 25.1-27.6 mm (based on complete specimens only), best width (opposite second third of wing length) 7.2-7.9 mm; $\mathrm{ScP}$ with strong and oblique 

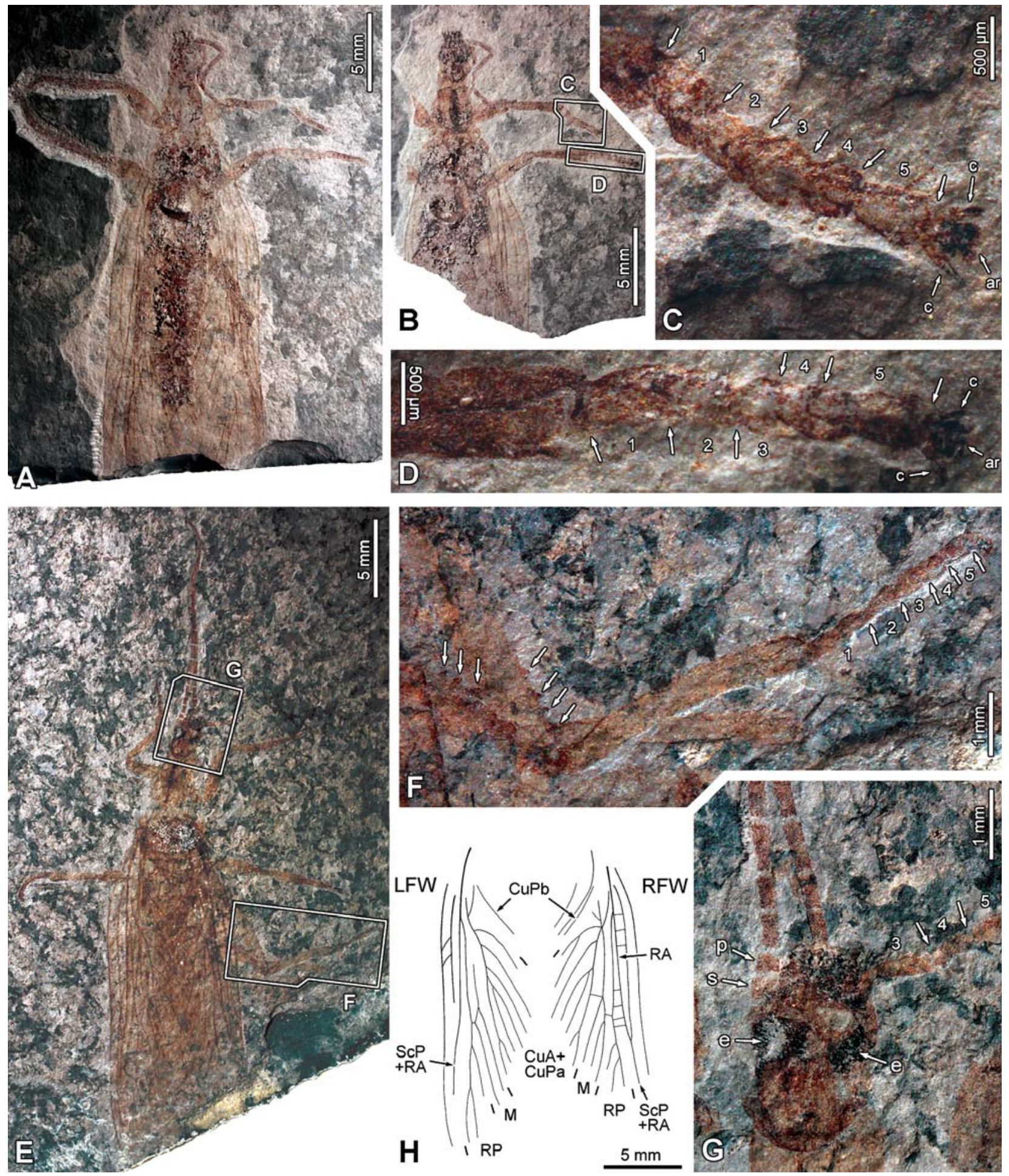

Figure 2. Miamia maimai n. sp.; A-D. Specimen CNU-NX1-278. A. Habitus (negative imprint, flipped horizontally); B. Habitus (positive imprint); C. Right fore-leg detail of tarsus as located on A (arrows indicate approximate segments limits); D. Right midleg detail of tarsus as located on A (arrows indicate approximate segments limits); E-G. Specimen CNU-NX1-319; E. Habitus (positive imprint); F. Hind-legs, details as located on E (along femora, arrows indicate spines; along tarsus, arrows indicate approximate segments limits); G. Head, details as located on E; H. Drawings of left and right forewings (for clarity, orientated as in E but separated).

veinlets, few with secondary fork, and reaching RA; RA and RP diverge at about the first fifth of wing length, basal of the divergence of $\mathrm{M}$ and $\mathrm{CuA}+\mathrm{CuPa}$; $\mathrm{ScP}+\mathrm{RA}$ simple; area between RA and RP narrow for long distance, broader basal to the end of $\mathrm{ScP}$ and on- wards; RP branched distal to its mid-length, usually distal to the end of ScP; RP usually with 8-9 branches reaching apex (6/8.6/12: $n=10)$, without consistent branching pattern; basal stem of $\mathrm{M}+\mathrm{CuA}$ close to $\mathrm{R}$ for some distance, then directed towards posterior wing 

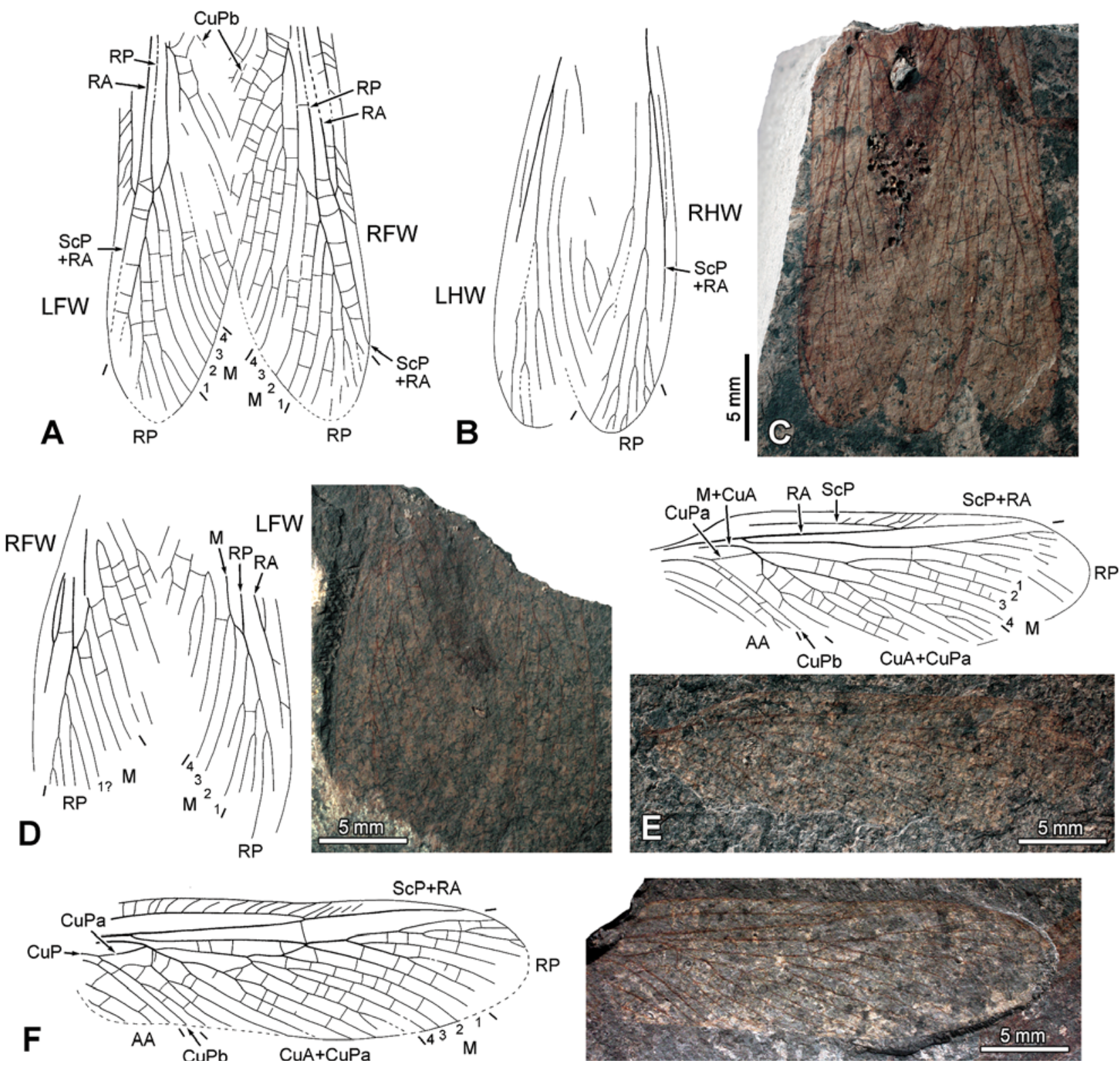

Figure 3. Miamia maimai n. sp.; A-C. Specimen CNU-NX1-273. A. Drawing of forewings; B. Drawing of hind wings; C. Photograph (negative imprint); D. Specimen CNU-NX1-275, drawing and photograph (negative imprint); E. Specimen CNU-NX1-274, drawing and photograph (right forewing, negative imprint, light-mirrored, flipped horizontally); F. Specimen CNU-NX1-277, drawing and photograph (right forewing, negative imprint, light-mirrored, flipped horizontally).

margin (opposite the point of divergence of RA and RP); $\mathrm{CuPa}$ usually fuses with $\mathrm{M}+\mathrm{CuA}$ for some distance, rarely at the point of divergence of $\mathrm{M}$ and $\mathrm{CuA}+\mathrm{CuPa}$; stem of $\mathrm{M}$ (diverging from $\mathrm{M}+\mathrm{CuA}+\mathrm{CuPa}$ ) simple for a long distance; $\mathrm{M}$ usually with four branches (3/3.7/5; $n=15$ ), usually dichotomously branched (i.e. pattern $(2,2)$ ); anterior branch of $\mathrm{M}$ (resulting either from the first or the second fork) usually fused with RP for some distance, more rarely briefly connected, or fusion absent (average RP - M condition $+0.27 \mathrm{~mm}$ ); area between $\mathrm{M}$ and anterior branch of $\mathrm{CuA}+\mathrm{CuPa}$ not particularly broad; $\mathrm{CuA}+\mathrm{CuPa}$ usually with $6-8$ terminal branches reaching posterior margin (5/6.9/9; $n=17)$, with a posterior stem usually with two branches, diverging obliquely; rare occurrence of $\mathrm{CuA}+\mathrm{CuPa}$ branche(s) diverging from $\mathrm{M}$, and from $\mathrm{CuPb} ; \mathrm{CuPb}$ simple; AA area with several veins.

Hind wing. ScP reaching RA distal to the wing midlength; RP diverging from $\mathrm{R}$ near wing base; area between RA and RP narrow for long distance; RP with numerous branches reaching apex.

Description. Specimen CNU-NX1-280 (holotype) (Fig. 1): nearly complete individual (Fig. 1A), very well preserved, positive and negative imprints, with head, legs and thoracic remains, almost complete forewings, left forewing in ventral view; head (Fig. 1D): $3.4 \mathrm{~mm}$ long; fastigium vertex broader than the scape; maxillary palpi strong, four segments visible, presumably with 5, 3rd, 4th and 5th segments of similar length; legs 

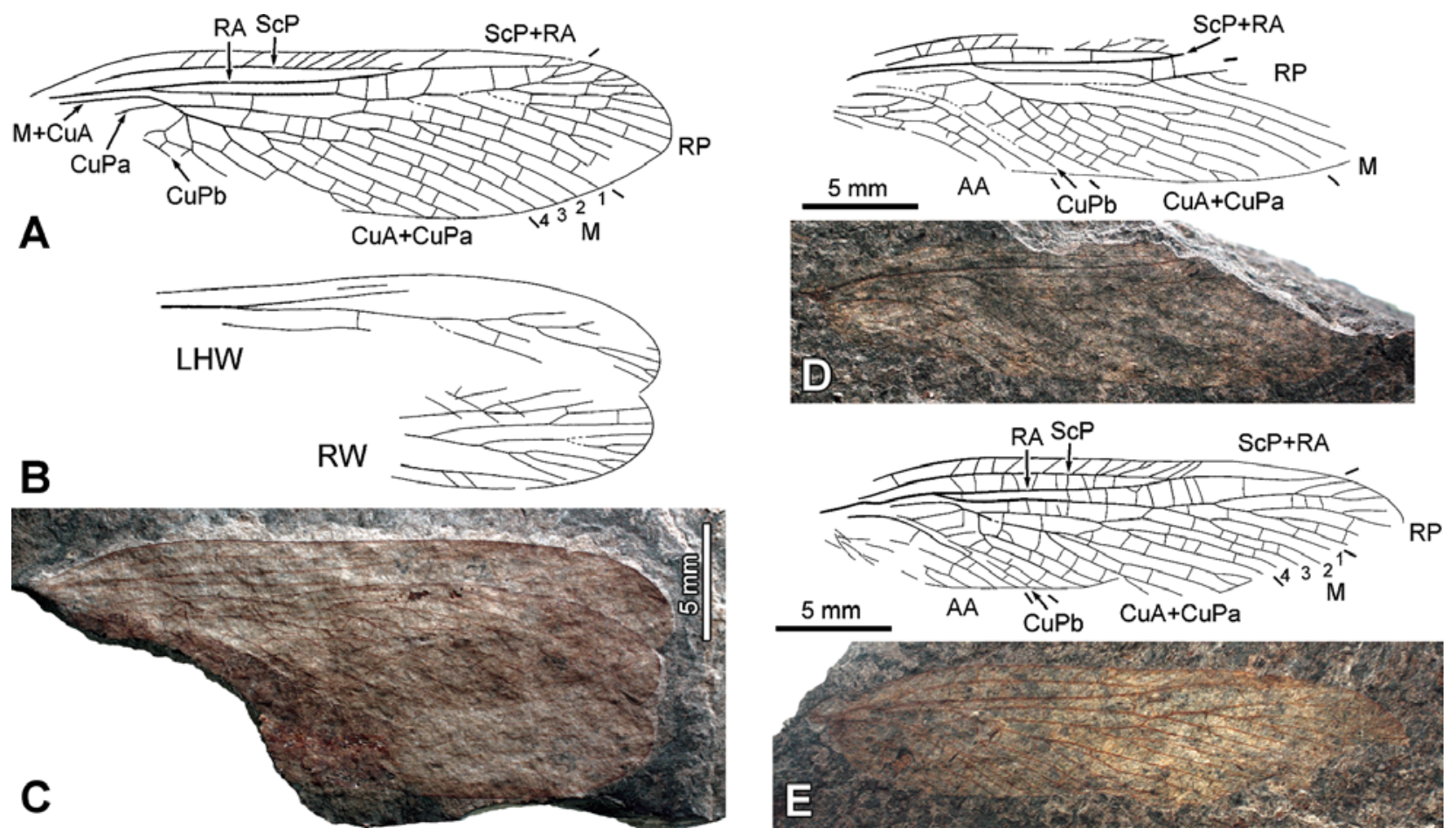

Figure 4. Miamia maimai n. sp.; A-C. Specimen CNU-NX1-272. A. Drawing of left forewing; B. Drawing of left hind wing and undetermined right wing; C. Photograph (positive imprint, flipped horizontally); D. Specimen CNU-NX1-279, drawing and photograph (right forewing, negative imprint, flipped horizontally); E. Specimen CNU-NX1-276, drawing and photograph (left forewing, negative imprint).

(Figs 1B-E): fore femora $3.7 \mathrm{~mm}$ long, $1.3 \mathrm{~mm}$ broad, stout and slightly dilated, with three small spines close to apex, located on ventral side (Figs 1B-C); fore tibiae $3.9 \mathrm{~mm}$ long; left fore tarsus $2.8 \mathrm{~mm}$ long, five-segmented (Fig. 1D); middle femora $3.2 \mathrm{~mm}$ long, middle tibiae $3.9 \mathrm{~mm}$ long, tarsi preserved in lateral position, 2nd and 3rd segments shorter and with ventral process projecting forward (Fig. 1E); forewing (Fig. 1F): left forewing length $27.0 \mathrm{~mm}$, best width (opposite second third of wing length) $7.4 \mathrm{~mm}$; left forewing: RP simple for $9.4 \mathrm{~mm}$, with 9 branches reaching wing apex; $\mathrm{M}$ simple for $6.9 \mathrm{~mm}$, fused with RP for $0.7 \mathrm{~mm}$; anterior branch of $\mathrm{M}$ fused with $\mathrm{RP}$ for $0.7 \mathrm{~mm}$; $\mathrm{CuA}+\mathrm{CuPa}$ with 6 terminal branches; right forewing: RP simple for about $9.3 \mathrm{~mm}$, with 4 branches preserved; connection of $\mathrm{M}$ and RP not preserved; $\mathrm{M}$ with 3 branches visible; $\mathrm{CuA}+\mathrm{CuPa}$ with 5 terminal branches.

Specimen CNU-NX1-278 (Figs 2A-D): nearly complete individual with overlapping wing pairs, positive and negative imprints (Figs 2A, B, respectively); head: $3.3 \mathrm{~mm}$ long; legs: fore coxae short, nearly as long as wide; femora $3.0 \mathrm{~mm}$ long, $1.1 \mathrm{~mm}$ wide; fore and middle tibiae $3.9 \mathrm{~mm}$ and $4.2 \mathrm{~mm}$ long, respectively; tarsi of both fore and middle legs well preserved (Figs $2 \mathrm{C}$, $\mathrm{D}$, respectively), preserved in dorsal orientation, with 5 segments, and well-preserved paired claws and arolium; ventral process (projecting forward) of $3 \mathrm{rd}$ and 4th segments visible.

Specimen CNU-NX1-319 (Figs 2E-H): nearly complete individual, with overlapping wings, positive and negative imprints; head - (Fig. 2G) $3.0 \mathrm{~mm}$ long; antennae complete, filiform, with 23 segments (or with just a few more terminal ones), inserted near the lower margin of eyes; scape and pedicel slightly broader than flagellum; legs (Figs 2E, F) middle tibiae $3.7 \mathrm{~mm}$ long; right hind femora $5.2 \mathrm{~mm}$ long, $1.0 \mathrm{~mm}$ wide, not dilated (possibly as a consequence of preservation orientation), with four small spines close to apex (ventral side); left femora with three small spines visible; left forewing (Fig. $2 \mathrm{H}$ ) preserved length $19.1 \mathrm{~mm}$; RP simple for $8.1 \mathrm{~mm}$, with 3 branches preserved; M with 2 branches preserved, connected to RP by a short crossvein (fused with RP and with more branches?); $\mathrm{CuPa}$ fuses with $\mathrm{M}+\mathrm{CuA}$ for $0.9 \mathrm{~mm}$; $\mathrm{CuA}+\mathrm{CuPa}$ with 7 terminal branches preserved; right forewing: preserved length $15.4 \mathrm{~mm}$; RP simple for $8.3 \mathrm{~mm}$, with 3 branches preserved; $\mathrm{M}$ distant from RP, with 3 branches preserved; $\mathrm{CuA}+\mathrm{CuPa}$ with 7 terminal branches preserved.

Specimen CNU-NX1-273 (Figs 3A-C): almost complete wing pairs, very well preserved, positive imprint; forewings: preserved length 22.2/22.0 mm (left/right forewing); RP with 8 branches visible; anterior branch of $\mathrm{M}$ fused with RP for $0.4 / 1.2 \mathrm{~mm}$; $\mathrm{CuA}+\mathrm{CuPa}$ with 7/8 terminal branches preserved; hind wings: ScP reaching RA; RP branched, with about 11 terminal branches covering apex.

Specimen CNU-NX1-275 (Fig. 3D): moderately well preserved forewing pair, negative imprint; left forewing: preserved length $17.9 \mathrm{~mm}$; RP with 4 branches preserved; M with 4 branches resulting from a $(1(1,2))$ 
branching pattern, anterior stem fused with RP for $1.1 \mathrm{~mm}$; right forewing: preserved length $16.7 \mathrm{~mm}$; M distant from RP, with 3 branches (fused with RP and 4 branches?); RP with 5 (6?) branches preserved.

Specimen CNU-NX1-274 (Fig. 3E): isolated right forewing, positive and negative imprints; wing length $25.1 \mathrm{~mm}$, best width $7.7 \mathrm{~mm}$; RP simple for $10.5 \mathrm{~mm}$, with 7 branches visible; $M$ simple for $5.2 \mathrm{~mm}$, distant from $\mathrm{RP}$; $\mathrm{CuPa}$ fused with $\mathrm{M}+\mathrm{CuA}$ at the point of divergence of $\mathrm{M}$ and $\mathrm{CuA}+\mathrm{CuPa} ; \mathrm{CuA}+\mathrm{CuPa}$ with 9 terminal branches, with inner reticulation.

Specimen CNU-NX1-277 (Fig. 3F): isolated right forewing, negative imprint; wing length $26.0 \mathrm{~mm}$, best width $7.9 \mathrm{~mm}$; RP simple for $9.9 \mathrm{~mm}$, with 7-8 branches visible; M simple for $5.3 \mathrm{~mm}$, anterior branch briefly connected with RP; $\mathrm{CuPa}$ fuses with $\mathrm{M}+\mathrm{CuA}$ for $0.3 \mathrm{~mm}$; $\mathrm{CuA}+\mathrm{CuPa}$ with 8 terminal branches, the most apical one diverging from $\mathrm{M}$, and another diverging from $\mathrm{CuPb}$ (as a consequence of fusions or translocations).

Specimen CNU-NX1-272 (Figs 4A-C): nearly complete left forewing, fragmentary left hind wing, and undetermined right wing, positive imprint; forewing length $27.6 \mathrm{~mm}$, best width $7.2 \mathrm{~mm}$; RP simple for $11.1 \mathrm{~mm}$, with 12 branches; $\mathrm{M}$ distant from RP; $\mathrm{CuPa}$ fuses with $\mathrm{M}+\mathrm{CuA}$ for $0.3 \mathrm{~mm}$; $\mathrm{CuA}+\mathrm{CuPa}$ with 8 terminal branches preserved.

Specimen CNU-NX1-279 (Fig. 4D): isolated left forewing, positive and negative imprints; preserved length $22.2 \mathrm{~mm}$, best width $6.3 \mathrm{~mm}$; RP simple for $7.7 \mathrm{~mm}$, with 3 branches preserved; $M$ simple for $3.9 \mathrm{~mm}$, anterior branch briefly connected with RP (or with more branches and a long fusion?); $\mathrm{CuPa}$ fuses with $\mathrm{M}+\mathrm{CuA}$ for $0.6 \mathrm{~mm}$; $\mathrm{CuA}+\mathrm{CuPa}$ with $7-8$ terminal branches, and an anterior veinlet fused with $\mathrm{M}$.

Specimen CNU-NX1-276 (Fig. 4E): isolated left forewing, negative imprint, posterior wing margin disrupted; preserved length $25.1 \mathrm{~mm}$, best width $6.1 \mathrm{~mm}$; RP simple for $9.3 \mathrm{~mm}$, with 7 branches visible; $M$ simple for $5.3 \mathrm{~mm}$, anterior branch fused with RP for $0.5 \mathrm{~mm}$; $\mathrm{CuPa}$ fuses with $\mathrm{M}+\mathrm{CuA}$ for $0.7 \mathrm{~mm}$; $\mathrm{CuA}+\mathrm{CuPa}$ with 8 terminal branches, with most anterior branch of $\mathrm{CuA}+\mathrm{CuPa}$ diverging from $\mathrm{M}$ (as a consequence of fusion or translocation).

\section{Discussion}

The species maimai exhibits the defining character state of the taxon Miamia as defined by Béthoux (2008a), namely 'in forewings, $\mathrm{CuPa}$ fuses with $\mathrm{M}+\mathrm{CuA}$ '. Provided with the available data, there is no reason to assume a convergent origin of this character state among the corresponding species, therefore maimai is to be assigned to Miamia. It can be argued that the defining character mentioned above can be considered as the only diagnostic character of the genus Miamia. If so maimai is to be assigned to this genus.

Specimens we assign to the new species exhibit some variation in size, but it is considered negligible, provided the variation observed in extant related species
(Adis et al. 2008; Ciplak et al. 2008; Picaud \& Petit 2008; among others). Additionally, variation in aspect ratio (and in size also) can be explained by plastic deformation, known to have affected the material from the Xiaheyan locality (Cui et al. 2011; Gu et al. 2011; Guo et al. in press).

The selected specimens show variation regarding several aspects of the wing venation pattern also. Variation in the number of $\mathrm{RP}, \mathrm{M}$, and $\mathrm{CuA}+\mathrm{CuPa}$ branches is consistent with that documented in M. bronsoni (revised in Béthoux 2008a). Variation regarding the fusion of a branch of M with RP (absent in M. bronsoni) are believed to account for intra-specific variation only, primarily because variation on this character among wings of a single individual is important (Figs $2 \mathrm{H}, 3 \mathrm{~A}$, D). In addition we observed a continuous range of conditions, including ' $\mathrm{M}$ and $\mathrm{RP}$ distinct' (Figs 3E, 4A), ' $\mathrm{M}$ and RP briefly connected' (Fig. 3F), 'M and RP fused for a short distance' (left forewing on Fig. 3A), and ' $M$ and RP fused for a long distance' (right forewing on Fig. 3A). We failed to find evidence of a multimodal distribution. In addition the same character was observed to be highly variable in loculata $\mathrm{Gu}$ et al., 2011 (see original description), another well-documented stem-orthopteran.

Yet regarding the $\mathrm{M}-\mathrm{RP}$ connection, there is a variation on the actual $M$ branch which fuses with RP: it is alternatively the anterior stem resulting from the first fork of $\mathrm{M}$ (i.e. 'M1' + 'M2'; left forewing on Fig. 3D and Fig. 4E), or the anterior-most branch only (i.e. 'M1'; Figs 1F, 3A, F). Provided the range of variation affecting this fusion, this variation cannot be considered as indicative of the occurrence of several species.

The rare occurrence of an anterior convex veinlet diverging from $\mathrm{CuPb}$ (Figs 3F, 4E) is believed to represent an intra-specific variation as well. The occurrence of veinlets in the area between the most posterior branch of $\mathrm{CuA}+\mathrm{CuPa}$ reaching the posterior wing margin, and $\mathrm{CuPb}$, is well documented in M. bronsoni, and are also occurring in M. maimai. It is conceivable that one of these veinlets translocates onto $\mathrm{CuPb}$. Several cases of a similar transformation, such as a $\mathrm{CuA}$ veinlet diverging from $\mathrm{CuP}$, have been documented in other polyneopteran insect groups, e.g. in grylloblattideans (Cui et al. 2011) and mantodeans (Béthoux et al. 2010). In these cases these variations occur at the intraspecific and intra-individual levels.

In two cases we assumed that a branch of $\mathrm{CuA}+$ $\mathrm{CuPa}$ diverges from $\mathrm{M}$ (Figs $3 \mathrm{~F}, 4 \mathrm{E}$ ). This interpretation is prompted by the assumption that the number of $\mathrm{M}$ branches is stable in this species. These particular cases can be explained by a fusion (some suspiciously strong cross-veins occur in the area between $\mathrm{M}$ and $\mathrm{CuA}+$ $\mathrm{CuPa}$ in both cases), or a translocation, of a branch of $\mathrm{CuA}$ with $\mathrm{M}$. The rare occurrence of a fusion of an anterior veinlet from $\mathrm{CuA}+\mathrm{CuPa}$ with $\mathrm{M}$ (Fig. 4D), and the fact that translocations commonly occur among insects at the specific level (OB, pers. obs.), suggest that these variations are not indicative of the occurrence of several species. 
In summary we found no ground for distinguishing distinct species among the selected specimens.

The new species is easily distinguished from Miamia species previously documented by (1) the stem of $\mathrm{M}$ simple for a comparatively long distance, and (2) the frequent occurrence of a fusion of a branch of $\mathrm{M}$ with RP. Both traits are absent in all species documented to date (M is longer in M. sylvatica than in M. bronsoni and $M$. rossorum, yet shorter than in M. maimai), and probably are plesiomorphies (see below).

In addition to the defining characters of Archaeorthoptera and Miamia, traits allowing the new species to be customarily distinguished from other species occurring at the Xiaheyan locality are its faint and weakly imprinted wing venation, and the lack of any particular coloration pattern.

\section{Discussion}

\section{Morphological and phylogenetic considerations}

The diagnostic character states of $M$. maimai are likely plesiomorphic conditions. The first of them, viz. a stem of $\mathrm{M}$ simple for a comparatively long distance, is common in lobeattid insects [an apomorphy-less assemblage of stem-orthopterans; among others, see Béthoux (2005)]. In contrast, Miamia spp. previously documented have a comparatively shorter stem of M. Similarly, the frequent occurrence of a connection between $\mathrm{M}$ and RP was observed in several lobeattid species (such as huangheense Prokop \& Ren 2007; see original description), but is absent in other Miamia spp. Therefore the combination of characters exhibited by M. maimai indicates that the species is a cousin relative of all other Miamia species (i.e. is plesiotypic with respect to all known Miamia species), and reinforces the view that Miamia derived from an undetermined lobeattid lineage (Béthoux 2008a).

Limited information on the morphology of Miamia spp. was available from the previous literature. Specimens with body remains other than wings are known for M. bronsoni only, and proved to be of difficult interpretation (Béthoux 2008a). The material of M. maimai provides new information on the morphology of these stem-orthopterans.

Regarding leg morphology, a 5-segmented tarsus with two terminal claws and an arolium was previously documented in the lobeattid species elongata Brongniart 1893: 433 (Béthoux 2009a). The occurrence of the same condition, probably plesiomorphic for orthopterans, was to be expected in Miamia. The occurrence of a 'process' projecting forwards, on the ventral side of at least the 2nd and 3rd tarsal segments (Figs 2C, D), and the proportion of the various segments, contribute to picture tarsi of $M$. maimai similar to those of stick- and leaf-insects (Fig. 5). To date the presence of 3-4 short and stout spines at the femur apex, in each leg pair (Figs 1B, C, 2F), has never been documented

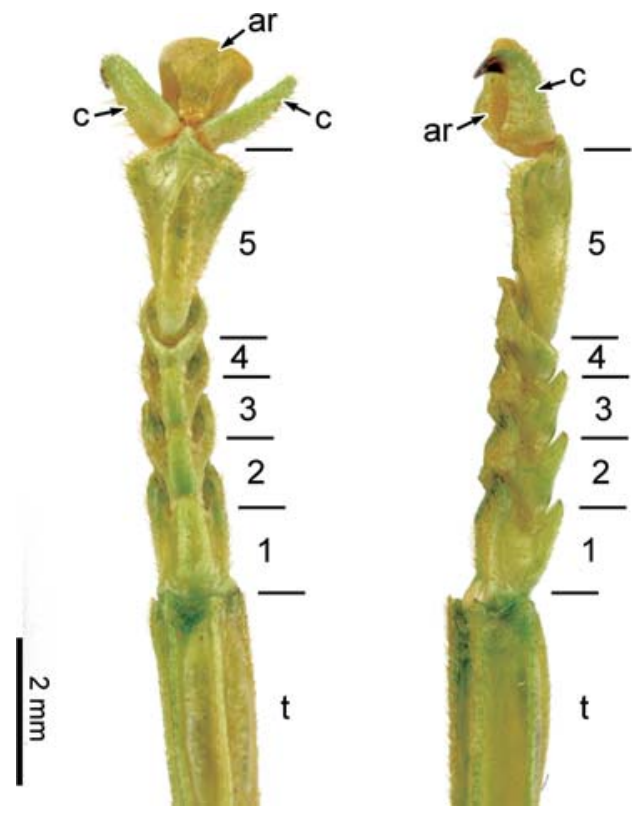

Figure 5. Species batesii Kirby, 1896 (peppermint stick-insect; assigned to genus Megacrania under the traditional procedure), mid-leg tarsus, dorsal and lateral views.

in any stem-orthopteran. Its phylogenetic relevance is unclear. Variation in width of femora within a specimen (e.g. CNU-NX1-278, Figs 2A, B) is deemed to be the consequence of differences in orientation, implying that femora were flattened and dilated.

Regarding the head morphology, it can be ascertained that M. maimai does not possess the impressive mandibules documented in the lobeattid elongata (Béthoux 2009a) and the (basal?) cnemidolestodean loculata (see $\mathrm{Gu}$ et al. 2011, figs 1.3, 4), of predatory type. However a more detailed account on morphology of these elements, and diet of the insect, is impossible, provided the available material. Labial palps were observed to be composed of four segments in the specimen CNUNX1-280, but it is likely that a first short segment, known to occur in orthopterans, among others, is hidden by other head remains.

\section{Space for nomenclatural experimentation}

Regarding animal species and taxa, actual experimentations on nomenclature are restricted by the need to comply with the International Code of Zoological Nomenclature (ICZN; until an alternative code is made available, if so). This partial test ban is the result of two aspects, namely whether taxa should be mandatorily associated to rank, and/or to a definition (and, if so, of which type), and whether species erected under a non-binominal procedure are valid, or not. The point of the relevance of rank vs./\& definition is not essential to address here, mostly because animal taxon names above the family group are not governed by any code, leaving an appropriate area for nomenclatural experimentation. In the current case, it can be argued that the name 'Archaeorthoptera' refers to a taxon above the ordinal 
rank, and therefore is not governed by any code, hence can freely be written in italics and associated to a definition (a usage to be followed under the cladotypic procedure). Reluctance to use binominal species names is more problematic, because the validity of species erected under this approach might be jeopardized.

Several options alternative to the binominal species names have been considered (Cantino et al. 1999), but few applied. Among those Lanham's species names, composed of the specific epithet associated with authorship information (Lanham 1965; Dayrat et al. 2004), have been favored and applied under the cladotypic procedure. The current case allows some discussion on this topic. Under the cladotypic procedure, the newly described species is to be referred to as 'maimai Béthoux, Gu, Yue \& Ren, 2012'. However, provided that it can be assigned to the 'genus-level' taxon Miamia, owing to the fact that the species exhibits the defining character state of this taxon (and assuming homology of the condition between the corresponding species), the combination 'Miamia maimai Béthoux, $\mathrm{Gu}$, Yue \& Ren, 2012' can be used as well. Just as a traditional binominal name, it mixes two distinct hypotheses, specifically one on the relationships of the species with others (i.e. assignment to Miamia), and another on the distinctiveness of the corresponding entity with respect to known species (hence referenced by a distinct name, viz. maimai Béthoux, Gu, Yue \& Ren, 2012). Names usage under the traditional and the cladotypic procedures can be equivalent: a first mention of 'Miamia maimai Béthoux, Gu, Yue \& Ren, 2012' could be followed by 'Miamia maimai', or 'M. maimai' alone. Basically, this is what is done above. However, four differences can be devised in the usage of species names as under the traditional and cladotypic procedures.

The first discrepancy regards the reference to species which generic assignment has been modified. For example, silvatica Laurentiaux \& Laurentiaux-Vieira 1980 was originally assigned to the monotypic genus Anthraconeura Laurentiaux \& Laurentiaux-Vieira 1980. This genus was synonymized with Miamia by Béthoux (2008a). Under the traditional procedure, the species should then be referred to as 'Miamia silvatica (Laurentiaux \& Laurentiaux-Vieira 1980)', but as 'Miamia silvatica Laurentiaux \& Laurentiaux-Vieira 1980' under the cladotypic one (i.e. without brackets delimiting authorship information). This difference is fairly superficial, and can even be judged inexistent if the traditional species name strictly is considered as Miamia silvatica only.

Another issue regards species provided with the same specific epithet in the same publication. If so, indication of the page on which the species has been described must be added (Lanham 1965; Dayrat et al. 2004). For example two 'elongatum' species were erected in Sellards (1909). The one assigned by Béthoux \& Nel (2010) to the taxon Phenopterum (itself adapted under cladotypic procedure, and previously considered as a genus name) was erected at the p. 156 in Sellards (1909), and is therefore to be referred to as 'elongatum Sellards 1909: 156', or as 'Phenopterum elongatum Sellards 1909: 156', under the cladotypic procedure. Discrepancy with 'Phenopterum elongatum Sellards 1909', as under the traditional procedure, is limited.

In order to keep species names stable, cladotypic nomenclature does not demand that gender of the specific epithet should be accorded to the gender of the corresponding taxon. Many users of the traditional procedure do not strictly follow this rule anyway (or even ignore it).

Finally, provided that maimai can be assigned to both the taxa Miamia and Archaeorthoptera, the combinations 'Archaeorthoptera maimai', 'Archaeorthoptera Miamia maimai', and 'Miamia maimai' are all possible under the cladotypic procedure. This is maybe the most significant discrepancy with the traditional procedure, but it can easily be circumvented for the sake of experimentation. In order to prevent contest on the validity of species erected under a cladotypic framework, an option is to use 'genus-level' taxon names adapted under cladotypic nomenclature (such as Miamia, Phenopterum), rather than 'ordinal-level' taxon names (such as Archaeorthoptera), in combination with the specific epithet. This is obviously restricting the advantages of Lanham's species names (Dayrat 2005), but is deemed to be necessary, at least temporarily. As a side effect, selecting and adapting previously existing 'genus-level' names would challenge the criticism that "renaming millions of taxa under new rules" would be necessary, should alternative nomenclatural procedures be applied (Dubois 2010, p. 261).

In conclusion the current case demonstrates that, as soon as an appropriate set of 'genus-level' taxon names is adapted under cladotypic nomenclature, it is possible to maintain the usage of binominal-like species names (at least temporarily), and erect new species in a way very similar to that resulting from the application of the traditional procedure. This 'resource-friendly' policy should facilitate experimental application of alternative nomenclatural procedures.

\section{Conclusions}

The abundance and preservation of material of $M$. maimai significantly improves our knowledge of the morphology of lobeattid insects. Variation in wing venation pattern, which is usually problematic to appreciate, and in particular for Pennsylvanian insects (Béthoux 2009b), is found to be significant. The relevance of many 'genus-level' contemporaneous and related taxa, erected based on characters observed in a single (or few) individuals, might have to be reconsidered.

The current case demonstrates that applying alternative nomenclature procedures can be performed in a way preventing newly erected species to be considered as invalid for lacking a binominal name (under the rul- 
ing of the ICZN). This is not to deny the fundamental differences existing between the various procedures (e.g. under the cladotypic procedure neither 'Miamia maimai' is a species name, nor Miamia a genus), but to make the point that there are means to test alternative procedures by a concrete practice. This possibly is the most sensible way to appreciate the optimality of the various procedures.

\section{Acknowledgements}

We thank two anonymous reviewers and A. Nel for their comments. We thank P. D. Brock for providing material of extant stick-insects. We thank Ying-Ying Cui, Yongjun Li, Liangjie Shang, Qiang Yang, and Xiaoguang Yang for contributing to the curation of the Xiaheyan fossil insect collection housed at the Capital Normal University (Beijing). This research is supported by the National Basic Research Program of China (973 Program, (2012CB821906), National Natural Science Foundation of China (No. 31071964), Scientific Research Key Program (KZ200910028005) and PHR Project of Beijing Municipal Commission of Education (20090509, 201107120).

\section{References}

Adis, J., Sperber, C. F., Brede, E. G., Capello, S., Franceschini, M. C., Hill, M., Lhano, M. G., Marques, M. M., Nunes, A. L. \& Polar, P. 2008. Morphometric differences in the grasshopper Cornops aquaticum (Brunner, 1906) from South America and South Africa. - Journal of Orthoptera Research 17 (2): 141-147.

Béthoux, O. 2005. Reassigned and new basal Archaeorthoptera from the Upper Carboniferous of Mazon Creek (IL, USA). - Journal of Orthoptera Research 14 (2): 121-126.

Béthoux, O. 2007a. Propositions for a character-state-based biological taxonomy. - Zoologica Scripta 36 (4): 409-416.

Béthoux, O. 2007b. Cladotypic taxonomy revisited. - Arthropod Systematics \& Phylogeny 65 (2): 127-133.

Béthoux, O. 2007c. Cladotypic taxonomy applied: titanopterans are orthopterans. - Arthropod Systematics \& Phylogeny 65 (2): 135156.

Béthoux, O. 2008a. Revision and phylogenetic affinities of the lobeattid species bronsoni Dana, 1864 and silvatica Laurentiaux \& Laurentiaux-Vieira, 1980 (Pennsylvanian; Archaeorthoptera). Arthropod Systematics \& Phylogeny 66 (2): 145-163.

Béthoux, O. 2008b. Groundplan, nomenclature, homology, phylogeny, and the question of the insect wing venation pattern. - Alavesia 2: $219-232$.

Béthoux, O. 2009a. Head and leg morphology of elongata Brongniart 1893: 433 (Late Carboniferous, Archaeorthoptera): phylogenetic and palaeoecological implications. - Annales Zoologici 59 (2): 141-147.

Béthoux, O. 2009b. Gaps and nodes between fossil and extant insects. - Systematic Entomology 34 (4): 599-609.

Béthoux, O. 2010. Optimality of phylogenetic nomenclatural procedures. - Organisms Diversity \& Evolution 10 (2): 173-191.

Béthoux, O., Beckemeyer, R. J., Engel, M. S. \& Hall, J. D. 2010. New data on Homocladus grandis, a Permian stem-mantodean (Polyneoptera: Dictyoptera). - Journal of Paleontology 84 (2): 746-753.

Béthoux, O. \& Briggs, D. E. G. 2008. How Gerarus lost its head: stem-group Orthoptera and Paraneoptera revisited. - Systematic Entomology 33 (3): 529-547.

Béthoux, O., Cui Yingying, Kondratieff, B., Stark, B. \& Ren Dong 2011. At last, a Pennsylvanian stem-stonefly (Plecoptera) discovered. - BMC Evolutionary Biology 2011 (11): 248.
Béthoux, O., Gu Junjie \& Ren Dong 2012. A new Upper Carboniferous stem-orthopteran (Insecta) from Ningxia (China). - Insect Science.

Béthoux, O. \& Jarzembowski, E. A. 2010. New basal neopterans from Writhlington (UK, Pennsylvanian). - Alavesia 3: 87-96.

Béthoux, O. \& Nel, A. 2001. Venation pattern of Orthoptera. - Journal of Orthoptera Research 10 (2): 195-198.

Béthoux, O. \& Nel, A. 2002. Venation pattern and revision of Orthoptera sensu nov. and sister groups. Phylogeny of Palaeozoic and Mesozoic Orthoptera sensu nov. - Zootaxa 96: 1-88.

Béthoux, O. \& Nel, A. 2010. Description of a new grylloblattidan insect from Montceau-les-Mines (Pennsylvanian; France) and definition of Phenopterum Carpenter, 1950. - Systematic Entomology 35 (3): 546-553.

Béthoux, O. \& Schneider, J. W. 2010. Description of a hind wing of a new basal Archaeorthoptera (Mazon Creek, IL; Pennsylvanian). Alavesia 3: 81-85.

Brongniart, C. 1893. Recherches pour servir à l'histoire des insectes fossiles des temps primaires précédées d'une étude sur la nervation des ailes des insectes. - Bulletin de la Société d'Industrie Minérale de Saint-Etienne (3) 7: 124-615.

Cantino, P. D., Bryant, H. N., de Queiroz, K., Donoghue, M. J., Eriksson, T., Hillis, D. M. \& Lee, M. S. Y. 1999. Species names in phylogenetic nomenclature. - Systematic Biology 48 (4): 790-807.

Cantino, P. D. \& de Queiroz, K. 2010. International code of phylogenetic nomenclature. Version $4 \mathrm{c}$.

Ciplak, B., Sirin, D., Taylan, M. S. \& Kaya, S. 2008. Altitudinal size clines, species richness and population density: case studies in Orthoptera. - Journal of Orthoptera Research 17 (2): 157-163.

Cui Yingying, Béthoux, O. \& Ren Dong 2011. Intraindividual variability in Sinonamuropteridae forewing venation (Grylloblattida; Late Carboniferous): taxonomic and nomenclatural implications. Systematic Entomology 36 (1): 44-56.

Dana, J. D. 1864. On fossil insects from the Carboniferous formation in Illinois. - American Journal of Science and Arts (2) 37 (2): $34-35$.

Dayrat, B. 2005. Advantages of naming species under the PhyloCode: an example of how a new species of Discodorididae (Mollusca, Gastropoda, Euthyneura, Nudibranchia, Doridina) may be named. - Marine Biology Research 1 (3): 216-232.

Dayrat, B. 2010. Celebrating 250 dynamic years of nomenclatural debates. In Polaszek, A. (ed.). Systema Naturae 250, The Linnaean Ark. CRC, London: pp. 185-239.

Dayrat, B., Schander, C. \& Angielczyk, K. 2004. Suggestions for a new species nomenclature. - Taxon 53 (2): 485-491.

Dubois, A. 2010. Zoological nomenclature in the century of extinctions: priority vs. 'usage'. - Organisms Diversity \& Evolution 10 (3): $259-274$

Gu Junjie, Béthoux, O. \& Ren Dong 2011. Longzhua loculata n. gen. and n. sp., one of the most completely documented Pennsylvanian Archaeorthoptera (Insecta; Ningxia, China). - Journal of Paleontology 85 (2): 303-314.

Guo Yinxia, Béthoux, O., Gu Junjie \& Ren Dong in press. Wing venation homologies in Pennsylvanian 'cockroachoids' (Insecta) clarified thanks to a remarkable specimen from the Pennsylvanian of Ningxia (China). - Journal of Systematic Palaeontology.

Hennig, W. 1966. Phylogenetic Systematics. University of Illinois Press, Urbana.

Kirby, W. F. 1896. On some new or rare Phasmidae in the collection of the British Museum (NH). - Transactions of the Linnean Society of London (2), Zoology 6: 447-475 + pl. 39-40.

Lanham, U. 1965. Uninominal nomenclature. - Systematic Zoology 14 (2): 144

Laurentiaux, D. \& Laurentiaux-Vieira, F. 1980. Un type singulier d'Insecte protorthoptéroïde du Westphalien supérieur du Pas-deCalais. - Annales de la Société Géologique du Nord 99: 407413. 
Liu Yushuang, Ren Dong \& Prokop, J. 2009. Discovery of a new Namurian archaeorthopterid from Ningxia, China (Insecta: Archaeorthoptera). - Zootaxa 2032: 63-68.

Lu Liwu, Fang Xiaosi, Ji Shuan \& Pang Qiqing 2002. A contribution to the knowledge of the Namurian in Ningxia. - Acta Geoscientia Sinica 23 (2): 165-168.

Peng Decheng, Hong Youchong \& Zhang Zhijun 2005. Namurian insects (Diaphanopterodea) from Qilianshan Mountains, China. Geological Bulletin of China 24 (3): 219-234.

Picaud, F. \& Petit, D. P. 2008. Body size, sexual dimorphism and ecological succession in grasshoppers. - Journal of Orthoptera Research 17 (2): 177-181.

Prokop, J. \& Ren Dong. 2007. New significant fossil insects from the Upper Carboniferous of Ningxia in northern China (Insecta: Palaeodictyoptera, Archaeorthoptera). - European Journal of Entomology 104 (2): 267-275.

Rasnitsyn, A. P. \& Aristov, D. S. 2010. New Eoblattida (Insecta) from the Permian of Russia. - Russian Entomological Journal 19 (1, 2): $13-20,122$.
Ren Dong, Nel, A. \& Prokop, J. 2008. New early griffenfly, Sinomeganeura huangheensis from the Late Carboniferous of northern China (Meganisoptera: Meganeuridae). - Insect Systematics and Evolution 38: 223-229.

Sellards, E. H. 1909. Types of Permian insects. Part 3. Megasecoptera, Oryctoblattinidae and Protorthoptera. - American Journal of Science (4) 27 (4): 151-173.

Zhang Zhijun, Hong Youchong, Lu Liwu, Fang Xiaosi \& Jin Yuegao 2006. Shenzhousia qilianshanensis gen. et sp. nov. (Protodonata, Meganeuridae), a giant dragonfly from the Upper Carboniferous of China. - Progress in Natural Science 16 (3): 328-330.

Zhang Zhijun, Schneider, J. W. \& Hong Youchong in press. The most ancient roach (Blattida): A new genus and species from the earliest Late Carboniferous (Namurian) of China, with discussion on the phylomorphogeny of early blattids. - Journal of Systematic Palaeontology. 